\title{
Comunidad y desarraigo. Aproximación al fenómeno pólis
}

\section{Community and uprootedness. An approximation to the Greek polis}

\author{
Aida MíGuez BARCIELA *
}

Universitat Pompeu Fabra

RESUMEN. Se contempla el rasgo definitorio del acontecer que llamamos «Grecia» desde dos vías confluyentes: el decir excelente griego (en especial el épos homérico) y el proyecto pólis. Concluimos que tanto el uno como el otro están marcados por la pretensión de hacer relevante aquello siempre ya dado por supuesto, confrontándonos con la gravedad de esta pretensión el hecho de que la pólis perezca precisamente por mor de lo que ella misma es.

Palabras clave: hermenéutica, poesía, héroe, distancia, nómos, pólis.

\section{Un principio metodológico: la sobriedad hermenéutica}

Empiezo recordando una especie de principio metodológico cuya asunción determina en gran parte nuestra capacidad de comprensión de cualquier fenómeno procedente de un ámbito distinto de la Modernidad. Me refiero a la sobriedad que consiste en tratar de conservar una clara mirada sobre el hecho de que una lectura hermenéutica no puede permitirse hacer valer sin cuestionamiento previo conceptos y categorías que en el mundo histórico del hermeneuta funcionan con el carácter de la obviedad. El hermeneuta, el esforzado lector moderno, debe más bien
Aвstract. The defining feature of the event that we call «Greece» is viewed through two meeting ways: the excellent Greek saying (especially the Homeric epos) and the polis-project. We conclude that both of them are marked by the attempt of recognizing what is always took for granted. The fact that the polis perish on account of what she is confronts us with the gravity of this attempt.

Key words: hermeneutics, poetry, hero, distance, nomos, polis.

procurar obtener conceptos y categorías consistentes a partir del fenómeno mismo a estudiar; ha de dejar que sea él mismo el que se los proporcione. Se trata, pues, de una actitud de respeto hacia la cosa, de una posición que permita que sea la cosa misma la que nos guíe proporcionándonos los conceptos adecuados para comprenderla. Esto quiere decir por de pronto que el hermeneuta debe apostar por mantenerse siempre alerta respecto a la proyección anacrónica de categorías que como moderno emplea con naturalidad, pues tal vez la conciencia de que ellas están ahí sea el primer paso para lograr que su operar irrestricto quede de algún modo bloqueado o en suspenso. 
Según este principio de sobriedad, en la posibilidad de comprensión de un fenómeno griego está en juego un doble movimiento: por un lado, la conciencia de que por nuestra parte opera una carga de supuestos instaura una actitud autocrítica que corrige nuestra visión previa, dado que siempre ya nos acercamos al texto desde alguna parte; decimos corregir, no eliminar, pues lo que no ocurre es que podamos trasladarnos exitosamente al otro lado. A la vez, el propio hundimiento en la cosa, poniendo de manifiesto que nociones para nosotros obvias no funcionan cuando se trata de leer por ejemplo un texto griego antiguo, tal vez instaure la actitud que consiste en consentir que la cosa misma se muestre bajo su propia luz, que sea ella la que nos dé las delimitaciones adecuadas para examinarla. La cosa que nos ocupa en estos momentos es la pólis griega. Puesto que se trata de un fenómeno específicamente griego nuestro principio de sobriedad nos impide de entrada subsumirlo bajo la categoría moderna «Estado»: la pólis no es la forma griega del Estado; es más, puede ser que la pólis no sea ni simplemente un estadio pre-estatal ni la correspondiente griega del Estado, sino el fenómeno cuyo acontecer asienta las bases para que pueda llegar a haber algo así como el «Estado», el cual presupone un estado de cosas exclusivamente propio de la Modernidad.

Este precepto de sobriedad hermenéutica afecta igualmente al uso que hacemos de categorías como «arte», «ciencia», «religión» e incluso «filosofía» cuando lo que queremos es en verdad referirnos a un fenómeno griego. También comporta la conciencia de la imposibilidad de que nuestras lenguas modernas puedan aportar equivalentes positivos para ciertas palabras de la lengua griega. Por ejemplo, ciertas palabras que traducimos por «tiempo», khrónos y aión, significan algo que no puede ser dicho sin más en una lengua moderna, a saber: el tiempo como lapso, tránsito, intervalo y distancia. Este significado nos plantea problemas como lectores modernos, pues para nosotros la ilimitación, la carencia de límites, es decir, el tiempo-ilimitado, es la representación obvia, la básica, de ahí nuestra dificultad para vérnoslas con palabras que en griego significan pura finitud. ${ }^{1}$ La cuestión de diferenciar con claridad cuál es en cada mundo histórico la representación básica tendrá importancia a la hora de aproximarnos a la cuestión «pólis». Por ahora, y según el aludido precepto de sobriedad hermenéutica, sólo hemos dicho que no podemos permitimos subsumir la pólis griega en el concepto moderno «Estado», y quizá esto pueda ponernos ya de entrada en actitud de atender al problema filosófico que supone la insalvable distancia de la Grecia antigua. Así, tal vez no podamos hablar de «arte» si lo que queremos es comprender el decir de Homero, ni de «religión» si queremos referirnos a las figuras de los dioses, tampoco de «ciencia» si queremos comprender la noción griega de saber. Y tal vez nuestro éxito como intérpretes consista precisamente en percibir esta distancia, en darnos cuenta de que inmediatamente no entendemos a los griegos.

Aquí nos preguntamos en qué sentido la noción de comunidad es una noción específicamente antigua, así como en qué sentido la comunidad griega, es decir, la pólis como el modo griego de acontecer la comunidad, consiste en un peligroso intento que quizá acabe comportando la pérdida de ella misma. Primero nos centramos en determinados aspectos de la Ilíada que nos conducen a una noción positiva de comunidad; después observamos algunas cosas en torno al modo en que allí mismo, en Grecia, aparece tanto la pérdida de la comunidad como la posibilidad de fundar comunidad. Esto nos situará ante la diferencia entre la pólis y el 
Estado, ante la distancia entre nosotros y los griegos, distancia que quedará también documentada con otras cuestiones internamente conexas con el problema de la pólis, a saber: qué se entiende en Grecia por conocimiento, cosa, dioses, poesía, etc.

\section{El decir excelente y el proyecto pólis}

De entrada nos referimos al épos homérico como uno de los fenómenos definitorios de eso que emerge de una «época obscura» en el a veces llamado «renacimiento del siglo octavo» ${ }^{2}$, fenómeno que forma figura con otros procesos por cuya irrupción decimos que Grecia nace; éstos son: la introducción del principio alfabético, cierto sello geométrico observable en la pintura sobre vasos, y el arranque de la pólis. Con «Homero» nombramos así cierto modo de decir cuidado que emerge desde una situación no simplemente sin escritura, pero sí sin principio alfabético $^{3}$, no sin asentamientos ni comunidad, pero sí sin el asentamiento y la comunidad peculiar que llamamos «pólis». Se podrían preguntar muchas cosas acerca del proceso que condujo a la fijación escrita de un poema monumental y unitario como la Ilíada tras un largo período de transmisión y composición exclusivamente oral, cómo era la práctica de los aedos prehoméricos, etc.; no seguiremos esta vía de análisis ni nos ocuparemos de la constitución de nuestro texto de la Ilíada (el problema de la fijación textual y su transmisión histórica); tampoco la utilizaremos a la manera de la historiografía común (de qué momentos cronológicos dan testimonio los poemas homéricos), sino que trataremos de concentrarnos en la cuestión estructural de «qué es» la Ilía$d a$, cuál es el espíritu del poema, pues será esta cuestión la que nos permita comprender el rasgo común a esos fenó- menos - principio alfabético, sello geométrico, arranque de la pólis - por cuya irrupción decimos que «Grecia» se constituye como tal.

Primero debemos matizar en qué sentido decimos que los poemas homéricos son decir cuidado, es decir, tenemos que explicar por qué hemos evitado las categorías «literatura» y «poesía» al referirnos a Homero. Recordamos dos cosas: 1. Por de pronto, eso que anacrónicamente describimos como un «poeta» no es en Grecia alguien que escribe un texto (aunque sí se sirve de la escritura), sino alguien que pone en ejecución un decir del cual forman parte inseparablemente las palabras, el gesto, la melodía, la danza...; el decir no tiene allí mismo lugar básicamente en el elemento de la escritura; el decir de Homero o de Píndaro no es en origen un texto para leer, sino para ejecutarlo de uno u otro modo dependiendo del género del que se trate. 2. Para definir consistentemente un género poético griego, en este caso el primero y más básico de ellos, el épos homérico, es necesario, y precisamente por la unidad de aspectos a la que acabamos de referirnos, que atendamos a la consistencia de los para nosotros diferentes planos en los que se realiza su estructura, es decir, que atendamos a la peculiar construcción del ritmo, la secuencia de los contenidos, la selección de las variantes de habla, etc. ${ }^{4}$ Aquí nos ocuparemos sólo de los contenidos de la Ilíada, y únicamente desde el punto de vista de la construcción de la trama.

El bastidor del episodio que relata la Ilíada - bastidor que no es el tema del poema, pero sí su horizonte presupuesto- es la confrontación entre dos grupos de gentes que en el poema aparecen caracterizados de algún modo como dos comunidades diferentes: la liga de varios contingentes procedentes de lo que por comodidad expositiva podemos llamar «Grecia» (gentes del Peloponeso, Tesa- 
lia, Beocia, las islas...) lucha contra Troya y los pueblos aliados que la apoyan (licios, tracios...). Prestaremos atención al episodio que narra la Ilíada empezando por ver qué elementos debemos tener en cuenta para comprenderlo.

La Ilíada se abre con la llegada de alguien especial al campamento de los aqueos, llegada cuyas consecuencias conducen a que uno de los más destacados guerreros aqueos, a saber, Aquiles, llame a la agorá, palabra que no significa aquí todavía el lugar de mercado en el centro de la pólis, sino la asamblea, la reunión: agorá es el substantivo del verbo ageíro, que significa «juntar», «reunir», si bien para reunir hay que contemplar separadamente y para separar hay que contemplar junto; se trata, como ocurre en el caso del verbo légein, de un juntar que a la vez discierne y separa. Por otro lado, tampoco cuando en la Ilíada se habla de "pólis» podemos asumir que con esta palabra se nombra ya lo que nosotros nombramos al hablar del «proyecto pólis», sino que básicamente se trata del establecimiento, del lugar donde se habita. Lo que aquí nos importa no es tanto la aparición de una u otra palabra como el hecho de que es el propio decir relevante homérico el que presenta en el fondo el mismo problema que el arranque de la pólis. De este proyecto es ciertamente constitutivo el que la agorá llegue a tener un papel central: ella es el lugar donde unos se encuentran con otros tanto como el lugar donde unas cosas se reúnen con otras, es decir, en ella se escenifica algún tipo de intercambio entre partes que pertenecen al mismo «en dónde», a la misma comunidad. Como es sabido, la agorá no tiene lugar en la comunidad no griega, por ejemplo en las comunidades que integran el imperio persa, desde cuyo punto de vista, construido a su vez por el griego Heródoto, la comunidad que instaura como centro de sí misma un espacio de intercambio interno aparece como una comunidad débil e inconsistente de la que no se debe tener miedo (cf. las palabras de Ciro sobre los griegos en Heródoto, I 153). Los persas, nos dice Heródoto, no conocen la agorá ni el intercambio dentro de la propia comunidad; ellos, a diferencia de los griegos, no escenifican el reparto de papeles, sino que simplemente están en él sin pretensión de transparencia o tematización alguna.

La Ilíada empieza precisamente con el llamamiento a la «reunión», al espacio en el cual unos se juntan y se separan de otros, al lugar donde cada uno aparece como el que en ese reparto es. Paradójicamente, lo que en esta inicial reunión de la comunidad aquea ocurre es que la figura que la ha convocado termina rompiendo con ella o ausentándose de ella. Aquiles - que llama a la reunión siguiendo una especie de voz o impulso divino (versos $\left.1.55 \mathrm{~s} .{ }^{5}\right)$ - , aparece en escena marcado por una ambigüedad: por un lado, él está implicado totalmente en la marcha de la empresa en la cual los aqueos están embarcados, y por eso llama a la asamblea; pero, a la vez, él es el que se va, el que desaparece y se retira del lugar de reunión. Expliquémoslo más exactamente.

En la reunión del conjunto de los aqueos tiene lugar el conflicto entre Aquiles y el representante de la empresa a la que el propio Aquiles pertenece, Agamenón; como consecuencia de esta disputa Aquiles se retira. La gravedad de la retirada reposa en el hecho de que quien se ausenta del combate es alguien que no puede entenderse sin él, alguien nacido para morir en él y sin el cual la empresa no alcanzará cumplimiento. De este modo, la figura de la cual depende la fuerza de la empresa común es a la vez aquella que se queda al margen de lo común. Con esta contradicción empieza la Ilíada. A efectos de la presente exposición sólo nos interesa subrayar dos ras- 
gos de la ruptura de Aquiles con la empresa común: por un lado, Aquiles se marcha no para irse a su casa, tampoco para adherirse a algún otro lado distinto que la empresa liderada por Agamenón, sino precisamente para quedarse en la pura distancia frente eso a lo que él mismo pertenece; por otra parte, Aquiles no se marcha solo, sino que se lleva a su propio contingente de guerreros, los mirmidones. Agravando esta situación de distancia se encuentra el hecho de que la ruptura de Aquiles con la empresa común, su desplazarse a algo así como «ninguna parte», esto es, su (parcial) desvinculación, ocurre en una situación donde cada figura está instalada en unas determinadas relaciones de vinculación, donde la distinción «dentro-fuera» no es gratuita sino consistente; una situación donde el punto de partida por de pronto obvio es la pertenencia a determinados vínculos, la efectiva presencia de un «en dónde» al que se pertenece. Esto queda documentado a nivel de los contenidos del poema a través de la importancia de cosas como el relato de la propia genealogía 6 , la relevancia de la adhesión a un determinado lugar de origen, las relaciones de lo que convencionalmente traducimos por «amistad», «comunidad», «camaradería» (philía, hetairía, philótes), «confianza» (pístis, pistós), etc. ${ }^{7}$ En el poema, la identidad de cada uno (la respuesta a la pregunta «quién eres») tiene tras de sí la presencia de determinados vínculos que a su vez implican determinados compromisos. Por ejemplo: Glauco y Diomedes se saben unidos por las relaciones de hospitalidad que una vez establecieron sus ancestros, de ahí que reiteren el antiguo vínculo intercambiando sus armaduras y acordando evitarse el uno al otro en el campo de batalla (versos 6.123ss.). La genealogía expresa la vinculación, la confianza y el compromiso, y esto pone ya de manifiesto la profunda diferencia respecto a la situación moderna, donde «yo» no estoy de entrada comprometido con nada ni pertenezco de entrada a nada. En Grecia opera en cambio la obvia pertenencia a determinados vínculos, a determinados contenidos, el compromiso con determinadas personas. La situación de vinculación es así en griego el punto de partida, de ahí que un «yo» griego no signifique lo mismo que un «yo» moderno: el griego presupone la implicación, la vinculación, el compromiso; el moderno la desvinculación, la nada, la no pertenencia, la situación donde «yo» es cualquiera, donde no hay nada que de suyo me pertenezca, donde todo contenido es para mí alienable, substituible y contingente. Por el contrario, la respuesta griega a la pregunta «quién eres» es, como se observa en el encuentro entre Glauco y Diomedes en la Ilíada, el relato de las relaciones de vinculación, es decir, la genealogía. ${ }^{8}$ De esta situación de efectiva pertenencia como punto de partida obvio es solidario el hecho de que alguien que carece de hogar y de ligamen con un determinado linaje no es nadie, es el más desgraciado y nulo de todos ${ }^{9}$, lo cual es un modo negativo de subrayar la importancia de las relaciones de vinculación en el horizonte del que los griegos son oriundos. También la historiografía muestra esto mismo: no eran los individuos aislados los que en un principio componían una pólis, sino determinados grupos (philai), formados por fratrías, formadas por linajes ${ }^{10}$, por más que resulte esencial al proyecto pólis la tendencia a que esto pierda cada vez más su validez, es decir, del proyecto pólis formará parte la tendencia a la uniformidad que disuelve los vínculos. En el punto de partida griego, es decir, en el decir de Homero, lo que ocurre es que incluso las cosas tienen su genealogía, y cuanto mayor es la importancia de la cosa tanto más extenso es el relato de su historia genealógi- 
ca. ${ }^{11}$ Este detallismo en el relato del aspecto o de la historia de una cosa es algo típicamente homérico que a los lectores modernos puede molestar, pero precisamente esta molestia que nos hace ver estos exhaustivos y detallísticos relatos como meras listas no es sino una evidencia de la incapacidad moderna para soportar la irreductibilidad de la cosa, para aceptar que una cosa no sea algo de lo que sin más puedo desprenderme. Para nosotros se trata de meros «catálogos» prescindibles; en griego, el katálogos señala la capacidad de katalégo, el decir la cosa de arriba abajo, en todo su detalle, en todos sus diversos, plurales e irreductibles aspectos.

La inicial pertenencia a determinadas cosas, es decir, la situación de vinculación como lo obvio, forma figura con otros aspectos solidarios de la actitud griega hacia el ser de la cosa:

La cosa no es en Grecia algo de lo que sin más pueda yo desprenderme, sino algo a lo cual estoy adherido, algo que de suyo me vincula a la hora de tratar con ella. La otra cara de esto es la noción griega de conocimiento, que no es dominio, sino algo así como respeto hacia el ser de la cosa. «Conocer» una cosa implica por tanto saber qué hacer con ella, entender cómo hay que tratarla, cómo requiere ser manejada, lo cual presupone una noción de saber que no es neutral respecto a lo que nosotros llamamos «las decisiones», pues tener el ser (ê̂dos) de la cosa a la vista es ya plegarse a ella, adoptar una determinada actitud o pauta de conducta respecto a ella. Por esta razón, el intérprete cuidadoso suele hacer notar que el «saber» griego (el «usar de», «servirse de», «andar con»: khráomai), a diferencia del nuestro, no suprime ni aplana, sino que descubre y reconoce el ser mismo de la cosa, siendo «las cosas» precisamente los contenidos de este «saber manejarse con» que no aplana ni domina, que no maltrata ni prostituye, sino que descubre y deja ser. A la vez, si la cosa tiene de suyo consistencia, consistencia a la cual el que conoce está adherido, es porque la cosa todavía guarda en sí un elemento de no-disponibilidad, de noaplanamiento, de no-explicación, es decir, todavía guarda en sí eso que los griegos llamaban «el dios». Nosotros diríamos: la cosa todavía alberga en sí la cuestión ontológica, y tiene sentido preguntarse por el «ser» de cada cosa porque el «es» todavía significa finitud, diferencia, delimitación, luz y belleza en el sentido de irreductibilidad.

Comunidad, presencia del dios en la cosa y noción de saber anterior a la escisión «conocimiento-decisión» son, por tanto, aspectos del horizonte del cual los griegos son oriundos. Ahora bien, ¿qué pasa cuando el dios no simplemente habita la cosa, sino que se hace presente en el decir de un dicente experto, de ese que anacrónicamente llamamos «el poeta»?, ¿qué pasa cuando la comunidad no simplemente funciona, sino que se trata de decirla, de hacerla transparente en su estructura interna; cuando se abre en su centro un espacio vacío de intercambio interno? En otras palabras: ¿qué ocurre cuando hay una sabiduría o destreza (sophía) no en este o aquel ámbito de cosas, sino en algo que no es ámbito particular alguno? Estamos ante la difícil y escurridiza cuestión de qué pasa cuando se pretende articular de alguna manera una referencia a aquello en lo que siempre ya se está y que, por tanto, pasa esencialmente desapercibido, no es nunca el objeto de atención.

Volvamos a la trama de la Ilíada. Decíamos que Aquiles aparecía en el poema como la figura que desaparece, como el excelente guerrero que rompe con la empresa común no para asentarse en alguna otra parte, sino para permanecer en la pura distancia respecto a la empresa mis- 
ma: Aquiles es la figura que no se subsume totalmente en el juego, sino que instaura una cierta distancia frente a él. Esta suspensión de la actividad tiene un desarrollo y unas consecuencias brillantes pero peligrosas, y ello tanto para la comunidad aquea como para el propio Aquiles. Veámoslo.

Sugerimos que lo extravagante de la ausencia de Aquiles consistía no en abandonar sin más la lucha, cosa que también, sino en marcharse de ella sin dar con un asentamiento alternativo. Aquiles se aleja a las tiendas con los suyos, percibiendo desde la lejanía los sucesos en la llanura de Troya, pero sin participar ya en ellos. Esta distancia, por serlo precisamente respecto a «lo común» (el ámbito a secas), es a la vez, y sin que se pueda eliminar la ambigüedad, tanto la suspensión o parálisis (epokhé) de la marcha de la empresa común como la posibilidad de que tenga lugar una visión profunda (sképsis) sobre la misma. Lo peligroso pero necesario de esta actitud de pura distancia radica en que ella comporta una especie de pretensión de afirmarse en la ausencia misma, de asentarse en la pura falta de asiento, es decir: de convertir en positivo algo que sólo puede ser negatividad, por más que sólo por la distancia pueda acontecer un discernimiento lúcido de la marcha del juego, el cual sin la distancia simplemente pasaría desapercibido, es decir, no acontecería, no se haría relevante. La distancia de Aquiles tiene, por tanto, dos caras o dos momentos esenciales.

Por un lado, la exterioridad de Aquiles permite que el juego no sólo se juegue, sino que acontezca de alguna manera, o sea, ella hace visible aquello que en el mero jugar el juego tranquilamente funciona, pero precisamente porque no se hace notar. La ausencia de Aquiles paraliza y pone en cuestión la fuerza de la empresa representada por Agamenón hasta tal punto que los aqueos se ven casi forza- dos a despedirse del objetivo de su viaje a Troya, pero precisamente la detención hace posible un examen crítico de la fuerza interna de la empresa común: precisamente porque Aquiles deja de participar, de actuar, de jugar el juego ordinario de la empresa en marcha, ésta puede hacerse relevante. Por otro lado, la posición distante que hace posible una visión no parcial del juego tiene, como hemos dicho, cierto carácter de instalarse en algo que impide la instalación, pues no tratándose de cosa alguna del juego, sino del juego como tal, es sólo pérdida, distancia y vacío, por más que la distancia sea el fuera que abre la posibilidad de ver y discernir el juego en su estructura interna. Como pretensión de habitar en cierto modo la «nada» necesaria para el reconocimiento la posición de Aquiles tendrá que romperse internamente. Aquiles tendrá que ser arrojado al suelo, y es relevante que observemos la manera en que esto ocurre.

Dijimos que la referencia ya no a un aspecto parcial del juego, sino al juego en su conjunto (la cuestión de lo que rige de antemano, la cuestión ontológica) requiere una distancia, pero, a la vez, esta distancia, por ser la visión de lo siempre ya supuesto, es distancia frente a todo, pérdida del lugar al que agarrarse. Observaremos qué implicaciones tiene el que esto sea así para comprender el fenómeno pólis, pero antes vamos a avanzar algo más en la cuestión de lo que podemos llamar la distancia escéptica de Aquiles.

El deseo de Aquiles (a saber: que se reconozca el carácter imprescindible de su fuerza para el éxito de la empresa que dirige Agamenón) en efecto se cumple: los mejores de los aqueos le expresan su reconocimiento, le suplican y le anuncian que Agamenón está dispuesto a subsanar su error con medidas compensatorias; más tarde, el conjunto del ejército conoce mediante el fracaso la precariedad a la que conduce una situación sin Aquiles. 
Sin embargo, el cumplimiento de su deseo es a la vez su incumplimiento, pues precisamente la penuria aquea acaba arrebatándole algo esencial para su propio equilibrio como figura, algo absolutamente necesario para el hecho mismo de que pudiese sostenerse en la distancia: Aquiles pierde a Patroclo, el más querido, el más amigo de todos (phíltatos). Es así como la comparecencia a través de la cólera del juego siempre ya supuesto se cumple finalmente como ruina, pues perdiendo a Patroclo lo que ocurre es que la distancia global se suprime a sí misma: es precisamente el Aquiles que se ha distanciado de todo quien no puede soportar perder el último de sus vínculos, el último hilo que le ata al suelo. Es él quien no puede en el fondo entenderse sin la pertenencia a comunidad alguna. Así, Patroclo, la figura que en el poema representa la imposible soledad de Aquiles, su inalienable pertenencia a ciertos vínculos, a cierta amistad, unión, philía, es precisamente la figura cuya muerte anticipa o representa la ruptura misma de la cólera. Así se cumple eso que Hölderlin ve llevarse a cabo en la celebración trágica: que la presencia del dios (esto es: lo siempre ya supuesto, la cuestión ontológica que ocultamente resplandece en cada cosa) es muerte. ${ }^{12}$ La muerte de $\mathrm{Pa}$ troclo muestra que la distancia necesaria para el reconocimiento del juego es pura negatividad, puro quedarse en el aire (en la no-ubicación, en la falta de arraigo), y que respecto a esto sólo cabe soportar la miseria, es decir, guardarse de pretender una referencia exitosa a lo siempre ya supuesto.

La imposibilidad de quedarse sin vínculo alguno o, lo que es o mismo, el carácter problemático de un distanciarse frente a todo contenido, es sentida en Grecia todavía como miseria y callejón sin salida. Esto es así porque, como hemos dicho, allí la cosa todavía tiene su dios, todavía guarda en sí un fondo impenetrable, un fondo que siempre se escapa y rehúsa la tematización. Porque todavía hay dios en la cosa, todavía se es consecuente con que el ser no es un ente ni es explicable a partir de ningún ente, de ahí que toda referencia a él sea viable sólo si acontece en forma de ruina y de desgracia. Dicho de otra manera: en Grecia la cuestión ontológica tiene lugar esencialmente como pérdida y caída de nuevo en el plano óntico, como retorno al primario estar cabe las cosas y escaparse siempre de nuevo la presencia del dios, del ser que habita ocultamente cada cosa. En la Ilíada esto se plasma en el hecho de que incluso el más solitario de todos los héroes no puede soportar la soledad absoluta, que con Patroclo muere también Aquiles mismo. El movimiento de la trama de la Ilíada responde así a la cuestión de cómo puede tener lugar una referencia a lo siempre ya supuesto, de qué carácter es la presencia que rompe con la cotidiana, ordinaria, regular y firme presencia de las cosas. Lo que así comparece es que la referencia a lo siempre ya supuesto sólo es viable en forma de rechazo, fracaso y ruina. La distancia global de Aquiles se cumple en efecto como referencia al juego en tanto que Aquiles pierde a $\mathrm{Pa}-$ troclo y sella con ello su muerte.

La miseria inherente al hecho de no pertenecer a nada aparece también en una de las palabras con las que Aquiles se ve a sí mismo desde los ojos de los otros. Se trata de la palabra metanástes, que suele emplearse para caracterizar a alguien que se ha ido a habitar a otra parte en la que, sin embargo, permanece como no integrado, como no instalado, de ahí que a veces se traduzca por «exiliado», «emigrante», «extranjero» o «refugiado». ${ }^{13}$ Lo interesante es que Aquiles no acepta en ningún caso ser tratado como un metanástes: la condición de alguien que ha perdido sus raíces no puede positivamen- 
te aceptada ni reivindicada, tampoco por Aquiles. Sin embargo, y a pesar de su rechazo a ser tratado como un exiliado sin morada, no otro que Aquiles es quien se ha negado a la vinculación y ha dado la espalda a la pertenencia a su más primario punto de partida - los vínculos y los contenidos-, exponiéndose así a los desastres de la desvinculación.

¿Por qué la ruina es necesariamente la otra cara del discernimiento del juego que hemos conectado con la cólera de Aquiles? La ruina es necesaria porque el ser no es nada en lo que quepa instalarse, porque no es un punto de llegada en el camino, sino algo que sólo comparece escapándose, es decir, que comparece como distancia, rechazo y negatividad. Dicho desde Parménides: el camino de la aletheíe consiste en romperse una y otra vez él mismo devolviendo al plano de las cosas, al plano de la dóxa. En la Ilíada es a través de la muerte de Patroclo como el dios da a Aquiles el golpe de gracia. Desnudándole, desnuda a Aquiles; exponiéndole a la muerte es a Aquiles al que expone. De nuevo se cumple eso de que el dios se hace presente en la no-figura de la muerte, pues tal vez sólo el dios pueda recorrer exitosamente el camino que conduce del ser al ente; para el hombre este camino es, sin embargo, intransitable.

El problema que se expresa en la figura de Aquiles es así el problema de cómo articular un camino (o mejor: no-camino, camino desconocido) que se desvía de la senda ordinaria de lo ente, del plano de la dóxa (el camino de «los muchos» en Heráclito), apuntando de algún modo a la cuestión «qué era ser»o «en qué consiste ser». ${ }^{14} \mathrm{El}$ problema de este camino es también el problema de la excéntrica órbita heroica, la cuestión de la extraña condición de «héroe». Veamos qué tiene que ver el héroe con el problema de la pólis.

\section{El héroe y la fundación de la pólis}

El que haya en efecto comunidad forma figura con el hecho de que siempre ya estamos cabe lo ente, siempre ya estamos adheridos a determinadas cosas, por más que en moderno esto presente serios problemas (recordemos: no significa lo mismo cuando un griego dice «yo» que cuando lo dice un moderno). Siempre ya estamos cabe las cosas, inmersos en ellas, tratando con ellas, y sin embargo aquello en lo que siempre ya nos encontramos deja algo atrás, en la presencia de la cosa algo queda siempre ya preterido. En otras palabras: la familiaridad de la morada oculta en sí la presencia desarraigante del dios, y los dioses son las figuras de las que el dicente excelente se sirve para señalar hacia ese fondo preterido en la cosa, a su irreductibilidad, a su elemento de no-disposición, algo que hemos conectado con la noción griega de saber y con la cuestión ontológica.

Aquiles es en la Ilíada la figura del reto de hacer relevante eso que siempre ya queda preterido, la figura de la distancia no externa, sino constitutiva, interna, frente a la propia comunidad; la figura que asume una hiperbólica separación frente a eso sin lo cual no puede entenderse. No en vano Aquiles conecta por su linaje con figuras divinas que no pertenecen al reino de Zeus, sino que quedan de algún modo atrás respecto al ámbito de la presencia que son Zeus y los olímpicos. El movimiento de la trama de la Ilíada escenifica la ruina inherente al reto de pertenecer a la no-pertenencia, de arraigar en el desarraigo, de quedarse sin contenido alguno. También en Heráclito (B 29) se ve cómo el héroe es esa figura que se distingue de «los muchos», es decir, del modo ordinario de estar cabe lo ente, precisamente por su capacidad para estar despierto, de prestar atención («guardar»: B 63) a algo que en la presencia cotidiana 
de lo ente inmediatamente no aparece; algo que está, pero preterido, inadvertido y oculto. Pero también en Heráclito el héroe es quien más muere, el que muere con los ojos abiertos: la figura que con su muerte muestra cómo la referencia a lo siempre ya supuesto es pura ruptura y rechazo; es ruina.

En la Ilíada los héroes son personajes que dejan atrás algo, figuras extraordinarias que tienen tras de sí un pasado cuya marca podríamos resumir en la fórmula crimen contra lo familiar, es decir, ruptura con lo acostumbrado y lo cercano, una ruptura que paraliza y suspende (cf. epokhé) por lo mismo que discrimina y ve (cf. sképsis). Tomemos como ejemplo la digresión genealógica sobre Tlepólemo que aparece en el llamado «Catálogo de las naves» de la Ilíada (2.653-670) a fin de observar la ruptura en la que consiste la litigiosa existencia de una pólis.

Sobre el dirigente de los rodios Tlepólemo el poeta cuenta que una vez cometió un asesinato contra un pariente suyo. A raíz de este delito tuvo que marcharse de su lugar de origen e irse a lo lejos, es decir, se vio obligado a la desvinculación, con la miseria que hemos dicho que en Grecia supone perder los vínculos y quedarse sin nada (algo que para nosotros no es un problema, pues partimos precisamente de la desvinculación): del Tlepólemo que ha perdido su obvia pertenencia a una comunidad se dice que huyó errando y sufriendo dolores, subrayándose así la miseria que comporta quedarse sin vínculo alguno. Sin embargo, no otro que el criminal Tlepólemo fue quien, llegando desde fuera, encontró asentamiento, se instaló, alcanzó morada (oikéo) en un lugar rodeado de mar por todas partes, una isla: Tlepólemo se transformó en el fundador de las tres póleis de Rodas. Nos interesa observar las dos caras del desarraigo de Tlepólemo, pues conectan con lo que hemos observado sobre la figura de Aquiles.

Por un lado, el crimen contra lo familiar y lo cercano (la hýbris) supone una dolorosa expulsión y un insoportable quedarse sin nada, quedarse fuera. El quedarse sin lo ente cabe lo cual siempre ya estamos es esterilidad, vacío o distancia, y la distancia es tomada en Grecia todavía como lo que es: pura negatividad, razón por la cual en la cosa un fondo siempre se escurre y por ello brilla ocultamente el dios, algo que hemos conectado tanto con la noción griega de «saber» como de «cosa». Por otro lado, la distancia implicada en el crimen contra lo familiar - la pérdida de las raíces - es a la vez la distancia inherente a la lucidez del conocimiento, a la claridad de la visión (versos 2.668-70: «fueron queridos por Zeus», «Zeus derramó sobre ellos indecible riqueza»). Se trata, por tanto, de un haber ganado cierta capacidad de sképsis, cierta visión exterior, visión que tanto en Homero como en Píndaro se relaciona con la capacidad de habitar y reconocer comunidad. Tlepólemo es así alguien que, habiéndose quedado sin comunidad, es adecuado para «habitar» (verso 668) la isla de Rodas (cf. sentencia del oráculo de Apolo en la olímpica séptima de Píndaro). Es adecuado porque ha roto, porque ha ganado la exterioridad necesaria para que acontezca el reconocimiento del estatuto que hace a la comunidad, reconocimiento que sin la distancia no acontecería.

Insistamos de nuevo en la noción de desarraigo como posibilidad específicamente griega, algo que está en íntima conexión con la posibilidad, también específicamente griega, de fundar comunidad en el sentido de reconocer su estatuto.

Hemos dicho que el griego parte de la presencia de vínculos y contenidos $\mathrm{y}$ desde ahí emprende el camino de ruptura con los mismos, un camino de desliga- 
miento y soledad el cual es sentido todavía como dolor y miseria. El desvinculado todavía puede por eso llorar, como llora Aquiles, la pérdida de la amistad: con el Aquiles que pierde a Patroclo Grecia pierde, quizá irrecuperablemente, la aproblemática pertenencia a los lazos, la natural cercanía a personas y a cosas, la ingenuidad del amor del estar entre las cosas. La trayectoria que va desde la comunidad al aislamiento no es sino la trayectoria más desarraigante de los griegos, que resulta ser inversa a la trayectoria moderna: nosotros, modernos, partimos de la ausencia de vínculos y contenidos, del original aislamiento y ausencia de morada, y desde aquí tratamos de reconocer algo, de dar con algún contenido. Esto se relaciona con lo que hemos dicho sobre la ilimitación como la representación básica moderna, lo cual forma figura tanto con la mercancía como concepto ontológico en la época moderna como con la nihilidad inherente a la forma legítima de Estado. En cambio, lo específico de la trayectoria griega consiste en que el desarraigo es todavía relevante; no así para nosotros, que carecemos de desarraigo simplemente porque no hay de entrada ningún arraigo posible, sino que de antemano nos movemos sobre la situación del haberse perdido toda posibilidad de desarraigo, y esto por la misma razón que los vínculos y los contenidos no constituyen en nuestro caso el punto de partida.

Hemos relacionado la pertenencia a la comunidad, la adhesión a determinados conjuntos de cosas, la amistad, con el hecho de que en lo más acostumbrado se oculte sin embargo el dios. La figura que hace patente esto, algo que para «los muchos» no se hace relevante, es precisamente el héroe. ${ }^{15} \mathrm{El}$ héroe es quien con su crimen muestra que en lo cercano y ordinario se oculta lo lejano-extraordinario, que la morada alberga en sí, ocultamente, lo divino: el desarraigo, lo inquietante, el misterio, la belleza. Y precisamente del proyecto pólis forma parte esa sentencia griega tan repetida de que «todo está lleno de dioses» y «en todo hay dioses», por lo cual podemos decir que la ruptura que hace posible que en la cosa se reconozca el dios (que Tlepólemo pueda fundar comunidad reconociendo su estatuto) no es otra cosa que la ruptura en la que consiste la propia pretensión pólis. En la pólis — en la morada - se celebra al dios —el desarraigo, la no-disponibilidad-. En lo más trivial —en la cosa- está lo que expulsa y desarraiga, pero a la manera del ocultamiento y del rechazo, por eso la mayoría, «los muchos», no saben nada de ello; el héroe, en cambio, es aquella figura marcada por la ruptura de un crimen, de ahí su brillo y excelencia, y de ahí también la capacidad de visión que hemos conectado con la posibilidad de fundar una pólis, es decir, con la difícil operación de reconocer el estatuto siempre ya supuesto. Del oikistér (el que habita, el que funda) decimos que reconoce el estatuto previo en el mismo sentido que decimos que Heráclito reconoce el reparto profundo en el que consiste el ser de lo ente, descubre el lógos, pero no lo instaura él mismo. Fundar es así conocer, y conocer es en griego saber manejarse; tal vez por eso Hölderlin habla no sólo de un destino más desarraigante entre los griegos, sino también de un destino más usurpatorio (de usurpatio: «manejo», «uso», «empleo» sentido enfático) en relación a la ley. ${ }^{16}$ Tanto el desarraigo como el saber usurpatorio portan en sí la idea de una distancia que permite descubrir y ver; el héroe y pólis son así dos caras del mismo fenómeno, pues la pretensión de la pólis no es sino la ruptura con lo óntico que hemos visto tanto en la trayectoria delictiva del héroe como en su competencia para fundar comunidad. Así, la pólis, en cuanto relevancia de eso 
que hemos relacionado con los dioses y la cuestión ontológica, está marcada por la misma transgresión (hýbris) que hemos observado en la figura de Tlepólemo, el desarraigado oikistér de las póleis de Rodas. ${ }^{17}$ Según esto, en la Modernidad no es posible ni el héroe ni el oikistér, pues se trata del ámbito o la época en la cual uno habita de antemano en un ámbito indiferenciado que impide pensar delimitaciones consistentes, no arbitrarias, y la comunidad es precisamente una delimitación, una diferencia consistente entre un «dentro» y un «fuera». Frente a esta situación la actitud filosófica moderna quizá consista en reconocer el estado de cosas tal cual es, es decir, en asumir el fenómeno de la mercancía, el derecho y la ciencia; en suma: la nihilidad. ${ }^{18}$

Finalmente decir que esos héroes destacados que asumen el reto de referirse al juego aun a costa de la ruina son personajes que dejan atrás una infancia, un crecimiento, un fondo, junto a un ser extraño, híbrido, que no pertenece ni a un lado ni a otro, que no es ni hombre ni animal, a saber: Quirón, un centauro. ${ }^{19} \mathrm{Se}-$ gún algunos decires, el ancestro de los centauros fue el fruto de los amores torcidos de un mortal marcado a su vez por haber sobrepasado el límite, es decir, por haber intentado dos cosas que comportan hýbris. Como consecuencia del castigo a la desmesura de Ixión nació Centauro, un ser solitario en tierra de nadie (Píndaro, pítica segunda). Asimismo, el centauro está asociado a la cuestión de qué deja atrás la comunidad pólis, qué queda de todos modos oculto en el espacio de claridad que el fundador abre en el interior de la pólis: la pólis deja atrás una vida no asentada, carente de establecimiento firme, un espacio agreste en bosques y montañas. A este espacio preterido se asocian ciertas criaturas cuya especialidad consiste en carecer de leyes y agorá, en desconocer el vino, etcétera; ciertas fi- guras caracterizadas por carecer de todo eso que hace al asentamiento pólis: los cíclopes. ${ }^{20} \mathrm{La}$ dos imágenes de la pólis que aparecen en el centro de la Ilíada, labradas sobre el escudo de Aquiles por el dios artista Hefesto, no son sino el establecimiento del hombre en la tierra, esencialmente conectado con el cultivo del suelo, la celebración de la boda, la asamblea y el litigio, la ganadería, el banquete, el sacrificio, el vino, la fiesta y el canto. Todo esto es desconocido para el centauro tanto como para el cíclope, si bien el centauro se diferencia en algo del cíclope, y precisamente por eso es él quien se ve involucrado en una constante lucha con los hombres. ${ }^{21}$

Podríamos preguntarnos por qué uno de los rasgos característicos de estos seres extraños es el desconocimiento del vino. Quizá por lo mismo que son excluidos de la pólis, pues la ambigüedad del vino es también la ambigüedad de la pólis: beber comporta cierta capacidad de ver las cosas desde la distancia, de relativizarlas, de transformarlas en lo que son en su existencia cotidiana, y esto es precisamente lo que hace la pólis: instaurar una distancia interna, incorporar una mirada foránea dentro de sí. Sin embargo, la fecundidad del vino depende esencialmente de la moderación con la que uno bebe ${ }^{22}$ : es esencial guardar la medida, beber y relativizar las cosas, pero no tanto como para que éstas se pierdan en una unidad indiferenciada en la que todo da lo mismo. Así también es esencial que la pólis concilie la ruptura con lo ente que la caracteriza con su permanecer una comunidad determinada, un límite; que la mirada que descubre el juego que siempre ya se está jugando no acabe precisamente en la pérdida del juego mismo. El problema de la pólis se presenta marcado por un difícil desafío: cómo ser en efecto una comunidad y a la vez hacer presente en el seno de sí misma el estatuto que la consti- 
tuye; cómo seguir habitando el límite y a la vez mencionarlo. Tal vez sea éste un intento suicida, pues las cosas funcionan precisamente cuando pasan desapercibidas; se mencionan cuando se las está perdiendo, y se pierden porque se las menciona.

\section{Nómos basileús}

¿Por qué la fundación de la pólis está asociada a la lucidez del haber perdido la morada, de haberse quedado en el aire, esto es, asociada a la distancia frente a todo contenido? Tal vez porque el proyecto pólis es el intento de que lo siempre ya supuesto (aquí: el límite y la comunidad) se abra, se diga, se ponga a la luz, a la vista de todos, y esto, la patencia de lo que podríamos llamar la ley profunda, anterior a los dioses y a los hombres, requiere la posición de distancia global que en Homero aparecía como el fatal estigma de la figura del héroe. El acontecer pólis está ligado de esta forma con la posibilidad de la distancia o la visión de aquel que, llegando como desde fuera, puede no simplemente jugar el juego, sino decir algo sobre él, puede verlo y reconocerlo como si lo viese desde arriba. Esto no es otra cosa que la actitud del theorós y del histor, aquellos que ven las reglas del juego porque no están totalmente subsumidos en él; están, pero con la nota fundamental de la distancia, distancia que permite el reconocimiento.

Alejando la pólis de cualquier situación moderna se encuentra el hecho de que lo que anacrónicamente llamamos «el poeta», que en Grecia es el diestro, el sabio (sophós) que descubre (poiể) la cosa en su ser, pueda ser a la vez aquel que legisla, el que da las leyes a la pólis. En este sentido, el poeta-legislador es un fenómeno exclusivamente griego. Y si fundar la pólis puede ser en efecto un acto del poeta (es decir, del sabio) es porque ante todo se trata de un acto de cono- cimiento. Recordemos que la pretensión de reconocer aquello en lo que siempre ya se estamos define tanto a la pólis como al decir excelente: la pólis es el proyecto de que el nómos (el reparto, el que esto sea esto y aquello aquello) se ponga a la vista de todos; el decir excelente es por su parte la pretensión de una destreza no en un ámbito de cosas particular, sino en aquello que la presencia de la cosa deja atrás: el poietés es el experto en el decir mismo, en légein, que no es sino el juntar-separar en el que consiste que haya cosas, es decir, el que esto sea esto y aquello aquello. En la historia del decir relevante griego ocurre que las figuras que tratan de mencionar eso siempre ya supuesto se sirven ocasionalmente de sendas palabras, lógos y nómos. Pensamos en el decir de Heráclito, pero también en Píndaro, en el fragmento $169^{23}$, que empieza con las palabras «nómos, el rey de todo, de mortales y de inmortales...». Comentándolo escribe Hölderlin que die strenge Mittelbarkeit ist aber das Gesetez («pero la estricta mediatez es la ley») ${ }^{24}$, y esto precisamente porque el nómos es la instancia anterior a los dioses y a los hombres, lo que está por encima de ambos sosteniendo su mirada recíproca, su diálogo, pero, precisamente por ser «lo más alto», no es nada, se escapa siempre. Esta reciprocidad, este estar-enfrente unos y otros, esta contra-posición (pólemos), es precisamente lo que los griegos oían en la palabra nómos. Intentemos ahora ver qué implicaciones tienen para la propia autocomprensión de la pólis estos versos de Píndaro.

Nos hemos referido al problema de un ver, reconocer o decir aquello en lo que siempre ya estamos. Con esto vinculamos el destino más desarraigante de los griegos, así como la capacidad de fundar comunidad. En la posibilidad de fundar o habitar estaba en juego un ver especial, el ver lo siempre ya dejado atrás, la no-onti- 
cidad que hemos relacionado con el ocultarse esencial del dios y la consiguiente consistencia de la cosa, la presencia de contenidos y la consiguiente pertenencia a una comunidad. Una de las palabras de las que los griegos se sirvieron para nombrar la no-onticidad preterida en cada cosa es, como hemos dicho, nómos, que significa algo así como «reparto» (verbo némein: repartir, adjudicar, distribuir; tener como parte, lote o porción). El lema de la pólis, eso por lo que desde sus inicios lucha, es precisamente la isonomía, donde el prefijo iso- señala que se trata de un uso hiperbólico de la palabra nómos. Isonomía nombra la pretensión de poner a luz el nómos que opera para todos y en todos los casos, que todos tengan a la vista el reparto siempre ya supuesto, que las leyes sean igualmente obligatorias para todos y que todos sepan igualmente a qué atenerse. La diferencia de la pólis frente a otras comunidades antiguas es justamente esta separación respecto a lo propio para poder obtener una visión sobre ello, un examen crítico, una theoría o una sképsis sobre eso en lo cual se habita. $\mathrm{O}$ sea: que la morada se haga relevante en cuanto tal, que el establecimiento se torne transparente, que se abra un claro en la espesura, claro que no es sino el espacio vacío en el medio, la agorá a la que unos y otros acuden para intercambiarse cosas y que escenifica una distancia interna. El espacio vacío en el medio es justamente eso de lo que carecen las comunidades persas, y en su existencia basaba Ciro su desconfianza frente a la fuerza de los griegos. ${ }^{25}$ Otra manera de expresar lo mismo la encontramos en algunas páginas de Heidegger, donde la pólis aparece caracterizada como el proyecto de fijar el pólos. ${ }^{26} \mathrm{El}$ verbo correspondiente a pólos, pélein, significa algo así como el moverse en general, y es una de las palabras griegas que, junto con eînai, pueden ejercer el papel de cópula; pólos es así el mo- verse mismo o lo que se mueve y gira sobre sí mismo (de ahí: «eje»). La comunidad griega, la pólis, se muestra otra vez como aquel peculiar tipo de establecimiento antiguo marcado esencialmente por la apertura de un espacio vacío que escenifica el eje en torno al cual todo gira; la pólis es por tanto ese extraño, atípico (o atópico) lugar donde el pélein-némein gana un espacio: el lugar donde «lo común» se pone «en el medio».

Uno de esos poetas-legisladores a los que hemos aludido es Solón, al que en su obra Heródoto introduce como un sophistés, alguien que ejerce de sabio sin que sea fácil o posible decir exactamente en qué ámbito de cosas el sabio es sabio (otra manera de expresar el mismo problema es decir que se trata de un sabio en los asuntos de la pólis). Pero precisamente Solón es también quien, una vez reconocido el nómos, emprende un viaje fuera de la pólis iniciando un peregrinaje que en Heródoto se llama theoría y se relaciona con la philosophía. No podemos analizar aquí en detalle este pasaje de Heródoto; en cambio aduciremos otro pasaje del mismo autor a fin de comprender por qué Solón se ve obligado, por mor de su propio carácter de legislador de la pólis, a ausentarse de ella.

Heródoto (VII, 101-104) relata como un antiguo rey de Esparta explica a Jerjes, actual rey persa, que los espartanos lucharán contra su ejército sean mil soldados, más o incluso muchos menos, pues los griegos poseen saber, coraje y nómos, y con ellos combaten la tiranía (desposýne) y la pobreza. Por esta razón, y por su aversión a la esclavitud, lucharán sea en las condiciones que sea. El bárbaro Jerjes sonríe; no comprende cómo tò politikón puede ser tal para los griegos. Por su parte, el antiguo rey griego, que declara haber sido él mismo expulsado de la pólis por los propios espartanos, siendo precisamente ésta la razón de su admira- 
ción hacia ellos, le responde: «los griegos son libres y a la vez no son libres: el nómos es para ellos el único señor, y es a él a quien temen más que a ti los tuyos». El bárbaro no entiende que los griegos puedan funcionar sin tener un monarca que los coaccione a ello, como tampoco podía entender la apertura de un espacio vacío de intercambio interno más que como engaño y debilidad. Sin embargo, la característica fundamental de las comunidades griegas consiste en apostar por que sea el propio nómos el que gobierne la pólis; si ésta es una sabiduría tiranicida es porque el nómos no es nada del hombre, sino algo previo al ser hombre el hombre y dios el dios, por lo que identificar la comunidad con un hombre concreto no sería sino incapacidad de reconocer el nómos mismo, ser débil en relación al proyecto pólis.

La connatural actitud tiranicida de la pólis es la razón por la cual Solón se va de viaje nada más haber reconocido el nómos, es decir, Solón se va para dejar que el espacio vacío en el medio, espacio que hemos relacionado aquí con la apuesta del héroe y el decir excelente, con el desarraigo y la capacidad de discernir lo siempre ya supuesto, permanezca como tal espacio vacío, como un «entre» en tierra de nadie. ${ }^{27}$ Solón se va, pues, para preservar la negatividad del vacío en torno al cual la pólis gira (pélei); mediante su ausencia permite que el nómos permanezca como lo que precisamente es, por eso su viaje aparece como una especie de respuesta isonómica al carácter de «entre» del espacio vacío en el cual la pólis intenta que el nómos comparezca. El viaje de Solón, del cual Heródoto dice que tuvo lugar por mor de la theoría y «filosofando», es, insistimos, la manera de hacer justicia a que no otro que el propio nómos es el basileús: es la ley quien concede toda autoridad, no la autoridad quien concede o decide la ley.
Para acabar dejaremos apuntadas ciertas incompatibilidades que surgen en Grecia a raíz del intento de ser comunidad y a la vez ser pólis.

Dijimos que la isonomía era la pretensión de que el nómos se pusiese a la vista de todos, es decir, que se fijase un sistema de reglas que fuese el mismo para todos y en todos los casos, sistema que tendrá que ser revisado una y otra vez, pues el nómos esencialmente se escapa. Esta fijación comporta sin embargo una dinámica de igualdad, pues todos están igualmente sometidos al nómos, de ahí que de cada nueva reconsideración del nómos se obtengan leyes cada vez más igualitarias, con lo cual se emprende un camino hacia la uniformidad y la pérdida de la diferencia, camino que resulta incompatible con el hecho mismo de la comunidad: el quién forma y quién no forma parte de la comunidad comienza a ser cuestión borrosa, comienza a convertirse en un problema. Junto a esto se encuentra el fenómeno de la acuñación de plata para servir de unidad en las transacciones, lo cual evidencia también una tendencia a la nivelación de la irreductible diferencia de cada cosa (las diferencias cualitativas entre las cosas tienen equivalencias cuantitativas en algo así como una sola cosa que sirve de mediador en los cambios). Finalmente, la isonomía resulta reinterpretada en algunos contextos como demokratía, y la diferencia entre ambas palabras es para nosotros relevante: isonomía no dice nada sobre quién tiene el «poder», sólo dice que hay un mismo nómos para todos y en todos los casos; demokratía, en cambio, dice que el krátos («poder» en el sentido de saber habérselas, cualificación), lo tiene el dêmos, noción que en griego comporta siempre el matiz de la indiferenciación y, por tanto, incompetencia y descualificación. Que el dêmos sea el que tiene el krátos, que él sea el sabio, cuando en el punto de partida griego, es decir, en Homero, el dêmos no 
es sino el personaje silente precisamente por incompetente, golpeado por el héroe cuando intenta abrir la boca, es otra de las caras donde se manifiesta la incompatibi- lidad que hace del proyecto pólis un proyecto suicida: el acontecimiento que se hunde precisamente por mantenerse en pie.

\section{NOTAS}

* Universitat Pompeu Fabra. E-mail: aida.miguez@upf.edu. El presente artículo se basa en una exposición oral que pronuncié en Vigo el 28 de enero de 2009.

${ }^{1}$ Cf. mi artículo «Aión, khrónos, Zeitlichkeit. ¿Qué tiempo originario?», Thémata. Revista de Filosofia, N. 41, 2009, pp. 238-252.

2 Cf. por ejemplo Latacz, J., Homer. Der erste Dichter des Abendlands, Düsseldorf-Zürich, Artemis \& Winkler Verlag, 2003, pp. 67/83.

3 Antes de la aparición del sistema de escritura alfabética, eso que la historiografía suele llamar la «Grecia micénica» ya conocía un sistema de escritura, si bien tal silabario no presenta la vocación de efectuar un análisis profundo de la lengua, vocación peculiar de la escritura alfabética.

4 Cf. Martínez Marzoa, F., El saber de la comedia, Madrid, Visor, 2005, pp. 13-31.

${ }^{5}$ Cito por la edición D. B. Munro y T. W. Allen, Oxford, 1920.

${ }^{6}$ Finley, M. I., «Household, Kin, and Community», en I. de Jong (ed.), Homer. Critical Assessments, London and New York, Routledge, 1999, vol. II, p. 151: «The profundity of the Greeks' kinship attachment, throughout their history, is immediately apparent from their passion for genealogies». Cf. también Raaflaub, K. A., «Homeric Society», en I. Morris, B. Powell (ed.), A New Companion to Homer, Leiden, New York, Köln, Mnemosyne Bibliotheca Classica Batava, 1997.

7 El adjetivo phílos significa algo así como «propio, de uno», de ahí: «querido, amado». De todos modos, algo queda aplanado en la traducción: mientras que para nosotros lo «propio» es algo de lo que siempre ya puedo desprenderme, alienable y frente al que «yo» estoy siempre más allá, el adjetivo griego phílos se refiere a algo de lo cual yo no puedo desprenderme sin más, algo que me atañe de tal forma que me vincula: «propias» son por ejemplo las manos y las piernas (cf. la posibilidad de emplear phílos como un posesivo).

${ }^{8}$ Las relaciones de amistad, hospitalidad etc. han de ser comprendidas en tanto que relaciones objetivas, no sentimentales, por más que a nosotros nos resulte tremendamente difícil comprender que las palabras griegas que así traducimos se refieren a estados de cosas, no a estados de la mente. Cf. Adkins, A. W. S., «Homeric Ethics», en I. Morris, B. Powell, op. cit., p. 708: «Philotes and xeinie are objective relationships, not dependent on the emotions of the partici- pants. (...) To say this is not to say that no Greek experienced any emotion in any relationship of philotes or xeinie; it is to say that emotion was not the common element that bound philoi together».

9 Glotz, G., «The Homeric City», en I. de Jong, op. cit. p. 107: «The man who had no genos behind him could obtain no redress against injustice».

10 Hornblower, S. y Spawforth, A., The Oxford Classical Dictionary, 3. ed., Oxford, 2003, s.v. pólis: «Socially the citizens comprised an ethnically homogeneous or limited group, organized according to "tribes" (philai) and smaller kinship groups, such as phratries, demes and families».

11 Cf. por ejemplo la descripción detallada del cetro de Agamenón en los versos 2.100-109.

12 Cf. Las notas de Hölderlin a su traducción de «Antígona».

13 Autenrieth, G. y Kaegi, A., Wörterbuch zu den Homerischen Gedichten, Sttutgart-Leipzig, 1999, s. v. metanástes.

14 Expongo más detalladamente una interpretación de la figura de Aquiles y las cuestiones a él asociadas en mi estudio Problemas hermenéuticos en la lectura de la Ilíada [en línea]. Barcelona. Universitat de Barcelona. Departament d'Història de la Filosofia, Estètica i Filosofia de la Cultura, 2008, $<$ D $>$ http://www.tesisenxarxa.net/TDX-0714108-123748/>

15 Desde el punto de vista de la cotidianidad el héroe aparece difícil, excesivo, asombroso, pero también divino, por eso la cercanía a los dioses de los héroes destacados, tanto por su linaje como por su asistencia en la situación pólemos; y no casualmente el héroe es aquella figura que pone en cuestión su propio ser en el ámbito de la confrontación, siendo precisamente pólemos una de las palabras de las que, junto con lógos o phýsis, se sirve Heráclito para designar el juego siempre ya supuesto.

16 Hölderlin, F., Sämtliche Werke. Kritische Textausgabe, Bd. 15, Hrsg. v. D. E. Sattler, Luchterhand Literaturverlag, Darmstadt, 1988, p. 287.

17 Que el desvinculado sea a la vez reclamado por el dios como el apto para fundar una pólis aparece en varias odas de Píndaro (cf. por ejemplo la novena oda pítica, donde el amor de Apolo por Cirene tiene que ver con lo mismo que hará de ella una arkhépolis, verso 51$)$.

18 Cf. Martínez Marzoa, F., «El pensamiento de Heidegger ante la brutalidad contemporánea», en Duque, F. (ed.), Heidegger. Sendas que vienen, Madrid, 
Círculo de Bellas Artes, 2008, sobre la peligrosidad de que en moderno se hable de algo así como «fundar Estado». A diferencia de los griegos, nuestro destino no es «más desarraigante», sino «más permanente». Ser capaces de reconocer sin engaños el propio punto de partida es saber mantenerse acorde con el «destino de una patria»».

19 Quirón es mencionado como educador de Aquiles en Homero, Il. 11.832, Píndaro, Pit. 6.21-3, Nem. 3.43-53, de Jasón en Pit. 4.102ss., de Asclepio en Pit. $3.5 \mathrm{ss}$.

${ }^{20}$ Cf. Gschnitzer, F., «Zur homerischen Staatsund Gesellschaftsordung: Grundcharakter und geschichtliche Stellung», en J. Latacz (Hrsg.), Zweihundert Jahre Homer-Forschung. Rückblick und Ausblick, Stuttgart-Leipzig, B. G. Teubner, 1991, p. 198.

21 El cíclope bebe leche, mientras que el centauro prueba el vino y se emborracha. La incapacidad para beber con medida es su distintivo, lo cual no hace sino reforzar su exclusión de la pólis que habitan los mor- tales. El vino es en Grecia lo que vivifica (de ahí el título que Hölderlin da al fragmento 166 de Píndaro: Das Belebende) y funda comunidad; también en él está el espíritu de la poesía.

22 Cf. por ejemplo Teognis, versos 467-510 y otros.

23 Cito por la edición Snell-Maehler, Leipzig, Teubner, 1980.

24 Hölderlin, op. cit., p. 291.

25 Martínez Marzoa, F., «Estado y pólis», en M. Cruz (compil.): Los filósofos y la política, FCE, México-Madrid.

26 Heidegger, M., Hölderlins Hymne «Der Ister» (Sommersemester 1942), Gesamtausgabe, Bd. 53, Frankfurt am Main, Klostermann, 1984, pp. 100s. También en el curso dedicado a Parménides reaparece esto mismo.

27 Cf. Ker, J., «Solon's Theôria and the End of the City», Classical Antiquity, vol. 19, n. 2, 2000, pp. 304-329. 